\title{
Caracterização do gerenciamento de projetos de software para m-business
}

\author{
Sidgley C. de Andrade ${ }^{1}$, Tania F. C. Tait ${ }^{1}$, Flávio M. de Oliveira ${ }^{2}$, Marcelo B. Ribeiro ${ }^{2}$ \\ ${ }^{1}$ Programa de Pós-Graduação em Ciência da Computação \\ Departamento de Informática - Universidade Estadual de Maringá (UEM) \\ Maringá - PR - Brasil \\ ${ }^{2}$ Programa de Pós-Graduação em Ciência da Computação \\ Pontifícia Universidade Católica do Rio Grande do Sul (PUCRS) \\ Porto Alegre - RS - Brasil \\ sidgley@gmail.com, tait@din.uem.br, \{flavio.oliveira, blois\}@pucrs.br
}

\begin{abstract}
Advances in computing and telecommunications have enabled the development of new technologies with spatial and temporal independence. Devices and servicesmobile are examples of this technology that drove the organizations to develop software to generate new prospects and business opportunities. The use of mobile technology as a business strategy involves a set of applications and services that are commonly called as m-business. This article aims to show the survey result that characterizes the software project management for mobile devices and identifies risks and challenges some companies about the project management for m-business.
\end{abstract}

Resumo. Os avanços nas áreas de computação e telecomunicação possibilitaram o desenvolvimento de novas tecnologias com independência espacial e temporal. Dispositivos e serviços móveis são exemplos dessa evolução tecnológica que impulsionou as organizações para desenvolverem software visando atender e gerar as novas perspectivas e oportunidades de negócio. O uso da tecnologia móvel como estratégia de negócio envolve um conjunto de aplicações e serviços que são denominados de m-business. Este artigo tem por objetivo apresentar o resultado da pesquisa de campo que caracteriza o gerenciamento de projetos de software para dispositivos móveis e identifica os riscos e desafios enfrentados por algumas empresas na gestão de projetos para m-business.

\section{Introdução}

A massificação dos dispositivos móveis fortaleceu-se ao longo dos últimos anos e à medida que foram adotadas pelos indivíduos as organizações também começaram a utilizá-las com o objetivo de expandir e gerar novas oportunidades de negócio [Machado e Freitas 2008]. Este fato deve-se a integração da computação, telecomunicação e tecnologia, e permite o desenvolvimento de soluções para atender os mais diversos segmentos de mercado.

Segundo o Relatório Anual 2010 [Anatel 2010] o número de acessos do Serviço Móvel Pessoal (SMP) cresceu 16,7\% em relação ao ano de 2009. Esse cenário representa um 
aumento gradativo causado, em grande parte, pelas novas tecnologias móveis e pela redução do custo dos dispositivos e serviços. $\mathrm{O}$ aumento representativo contextualiza e ratifica a adoção da tecnologia móvel tanto no segmento pessoal como no organizacional.

O uso predominante da tecnologia móvel como estratégia de negócio envolve um conjunto de aplicações e serviços que são comumente denominados de $m$-business. Assim como o termo eletronic se popularizou e definiu os diversos segmentos de negócios na Internet, por exemplo, e-business, e-commerce e e-marketing, as soluções móveis também herdaram a mesma terminologia para dividir seus ramos de aplicação. Os termos m-business, m-commerce e m-marketing, dentre outros, são corretos e designam o contexto da solução do negócio móvel. No meio organizacional é comum à denominação m-business para as soluções de problemas que exigem a aplicação de tecnologias móveis [Machado e Freitas 2008]. No entanto, o desenvolvimento de softwares para $m$-business é caracterizado por uma série de incertezas e desafios que envolvem desde a concepção das aplicações e serviços [Fouskas et al. 2005] até o desenvolvimento do software final. Entender essa modalidade de desenvolvimento de projetos de software exige uma abordagem de pesquisa estratégica e multidisciplinar [Fouskas et al. 2005][Machado e Freitas 2008][Unhelkar 2009].

O presente artigo tem por objetivo apresentar o resultado de uma pesquisa de campo que caracteriza o gerenciamento de projetos de software para negócios móveis. $\mathrm{O}$ estudo exploratório identifica os riscos e desafios enfrentados por algumas empresas brasileiras na gestão de projetos de desenvolvimento de software para dispositivos móveis.

Este artigo está estruturado da seguinte forma: a seção 2 trata do projeto de pesquisa; na seção 3 é apresentada a metodologia do projeto de pesquisa; na seção 4 a etapa de planejamento da pesquisa é especificada; na seção 5 a execução da pesquisa é relatada; a seção 6 descreve sucintamente a análise e interpretação dos dados coletados na etapa de execução; os resultados da pesquisa encontram-se na seção 7; na seção 8 são abordados três trabalhos relacionados e nas seções 9 e 10 são apresentados, respectivamente, as considerações finais e os agradecimentos.

\section{Projeto de pesquisa}

O projeto de pesquisa determina uma investigação em retrospecto da gestão dos projetos de desenvolvimento de software para dispositivos móveis. A pesquisa tem por objetivo analisar a organização, os colaboradores, os produtos e os processos no contexto de $m$-business com o propósito de explorar e caracterizar a forma do gerenciamento com respeito aos riscos e desafios a partir da perspectiva dos gerentes de projetos e desenvolvedores de software - visa identificar as lacunas e os desafios na forma como as empresas definem e conduzem os projetos de desenvolvimento de software para $m$-business.

O levantamento de dados para a pesquisa abrangeu 03 (três) empresas brasileiras, uma situada no Estado do Paraná (PR) e duas no Estado do Rio Grande do Sul (RS), cujo desenvolvimento é estrito para aplicações móveis. Para preservar os participantes da pesquisa, os nomes das empresas são referenciados como "Empresa E1", "Empresa E2" e "Empresa E3” e os colaborados por meio do cargo ou função exercida. As empresas são classificadas como pequenas e atuam nos seguintes segmentos: as empresas "Empresa E1" e "Empresa E2" desenvolvem aplicações móveis para força de venda e a "Empresa E3” aplicações móveis sob a forma de software como serviço. 


\section{Metodologia do projeto de pesquisa}

As etapas da metodologia do projeto da pesquisa basearam-se nos trabalhos do Yin (2005) e Mafra e Travassos (2006) e são compostas por um planejamento, uma execução, uma análise e interpretação dos dados e uma apresentação dos resultados (Figura 1). As técnicas e os instrumentos utilizados na pesquisa são apresentados na etapa de planejamento.

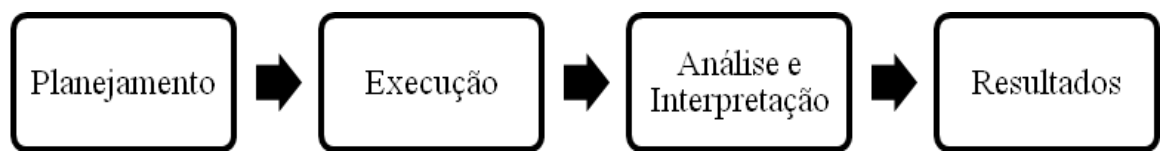

Figura 1. Etapas do processo de pesquisa

É essencial que antes da especificação do planejamento os objetivos da pesquisa estejam definidos e claros. O objetivo principal desta pesquisa foi realizar um levantamento exploratório em empresas que desenvolvem software para soluções móveis com o propósito de detectar as características e os problemas ligados ao gerenciamento de projetos de software. Como objetivos específicos foram definidos:

- Conhecer a estrutura organizacional da empresa.

- Levantar dados dos softwares desenvolvidos e/ou utilizados nas soluções móveis.

- Identificar os problemas detectados sob a ótica gerencial.

- Identificar os problemas detectados sob a ótica dos desenvolvedores de software.

- Relacionar o levantamento de dados com o tema de negócios móveis.

\section{Planejamento da pesquisa}

Na etapa de planejamento o projeto de pesquisa e a seleção dos instrumentos do estudo são definidos [Yin 2005][Mafra e Travassos 2006]. As questões primárias e secundárias que direcionam o pesquisador no campo e as proposições que auxiliam na análise e confiabilidade dos dados, em confronto com as questões de pesquisa, são especificadas. As unidades de análise, as fontes de evidência e os protocolos de coleta de dados também são incorporados no plano do projeto de pesquisa.

No desenvolvimento do planejamento buscou-se mitigar dois possíveis problemas apresentados por Yin (2005): a falta de rigor da pesquisa em relação as evidência e as visões tendenciosas e a insuficiência de evidências para triangular e corroborar os resultados. Como resultado desta etapa elaborou-se um documento denominado plano do levantamento exploratório. Em suma, a Tabela 1 apresenta os principais itens constantes deste plano.

Tabela 1. Itens do plano do levantamento exploratório

\begin{tabular}{ll}
\hline Itens & Descrição \\
\hline Questões de & 1. Quais são as características e problemas encontrados no gerenciamento de \\
estudo & projetos de software para negócios móveis? \\
& 2. Quais são as características que diferem o gerenciamento de projetos para \\
& negócios móveis em relação ao gerenciamento clássico? \\
& 3. Quais são e em que momento do projeto ocorre os problemas específicos do \\
& gerenciamento de projetos de software para soluções móveis? \\
\hline
\end{tabular}


Tabela 1. Itens do plano do levantamento exploratório (continuação)

\begin{tabular}{|c|c|}
\hline Itens & Descrição \\
\hline $\begin{array}{l}\text { Questões de } \\
\text { estudo }\end{array}$ & $\begin{array}{l}\text { 4. A adoção de alguma prática (modelo ou metodologia) pode mitigar ou eliminar } \\
\text { esses problemas? }\end{array}$ \\
\hline Hipótese nula & $\begin{array}{l}\text { O gerenciamento de projetos de software é o mesmo para todas as modalidades } \\
\text { de aplicações. }\end{array}$ \\
\hline Proposições & $\begin{array}{l}\text { - Requer uma estrutura tecnológica e de mapeamento de riscos mais complexa. } \\
\text { - Fatores regulatórios são riscos do projeto relacionados aos fatores externos. } \\
\text { - A infraestrutura de comunicação e a incompatibilidade tecnológica são } \\
\text { características/problemas encontrados no gerenciamento de projetos de software } \\
\text { para negócios móveis. } \\
\text { - Os recursos humanos devem possuir habilidades multidisciplinares. }\end{array}$ \\
\hline $\begin{array}{l}\text { Unidades de } \\
\text { análise }\end{array}$ & $\begin{array}{l}\text { - Organização } \\
\text { - Produto } \\
\text { - Indivíduo } \\
\text { - Processo }\end{array}$ \\
\hline $\begin{array}{l}\text { Fontes de coleta } \\
\text { de dados }\end{array}$ & $\begin{array}{l}\text { - Documentação (organização, produto, processo) } \\
\text { - Registro em arquivo (organização, produto, indivíduo) } \\
\text { - Observação direta (organização, indivíduo) } \\
\text { - Entrevista semiestruturada (produto, indivíduo, processo) }\end{array}$ \\
\hline Itens de coleta & $\begin{array}{l}\text { - Estrutura organizacional } \\
\text { - Cultura organizacional } \\
\text { - Escopo dos produtos } \\
\text { - Indicadores de qualidade } \\
\text { - Indicadores de produtividade } \\
\text { - Comunicação entre os membros da equipe } \\
\text { - Conhecimento dos membros da equipe sobre gerenciamento e desenvolvimento } \\
\text { - Conhecimento dos membros da equipe sobre os produtos } \\
\text { - Processo de desenvolvimento } \\
\text { - Mapeamento dos processos } \\
\text { - Modelo ou metodologia de gerenciamento projetos } \\
\text { - Aderência ao modelo de gerenciamento de projetos }\end{array}$ \\
\hline
\end{tabular}

\section{Execução da pesquisa}

A execução do plano do levantamento exploratório ocorreu entre os meses de Junho e Julho de 2011. Para alcançar o resultado esperado, refutar a hipótese nula e confirmar ou negar as proposições de pesquisa, definiram-se 04 (quatro) fases fundamentadas nos trabalhos de Yin (2005) e Mafra e Travassos (2006):

- Preparação: seleção dos participantes e preparação dos documentos, das técnicas e dos instrumentos de coleta de dados a partir das questões definidas na etapa de planejamento. Determina como executar uma instância do plano do projeto de pesquisa.

- Coleta: aplicação dos documentos e das técnicas da fase de preparação. Execução das instâncias do plano do projeto de pesquisa. 
- Análise preliminar: organização e compreensão dos dados coletados para a aplicação da técnica de confiabilidade.

- Confiabilidade: aplicação de técnicas para ratificar os dados obtidos dos itens de coleta de dados da etapa de planejamento.

A fase de preparação, cujo alinhamento entre o planejamento e a pré-execução é analisado, permitiu identificar obstáculos e restrições de impacto na execução do estudo, muitos alertados por Yin (2005) como instigadores dos possíveis problemas apresentados na etapa de planejamento da pesquisa. Dentre os obstáculos e restrições estão:

- Tamanho da amostra: limitação do número de participantes na pesquisa. Tamanho da amostra limitado para a aplicação de determinadas técnicas.

- Seleção dos participantes: seleção por conveniência dos colaboradores devido fatores organizacionais, geralmente ligados a nível hierárquico e disponibilidade.

- Restrição das fontes de coleta de dados: apenas alguns instrumentos de pesquisa são permitidos para a coleta de evidências, geralmente decorrentes de fatores organizacionais.

- Validação dos dados: ausência de diferentes pontos de vista e fontes de evidência impossibilita a aplicação de técnicas para a validação e a confiabilidade dos dados. Inviabiliza a triangulação dos dados.

Esses obstáculos e restrições são ameaças em estudos dessa natureza, contudo é difícil ou inviável elaborar ações para minimizar os efeitos e os impactos na execução do plano do projeto. Nas situações em que o pesquisador possui acesso antecipado na empresa e conhece ou consegue identificar os possíveis respondentes é aconselhado que sejam previstas e elaboradas estas ações na etapa de planejamento.

O número reduzido de colaboradores nas empresas influenciou na seleção adequada dos participantes (tamanho da amostra), impossibilitando a participação de pessoas com cargos e funções distintas, bem como dificultando a confirmação dos dados na fase de coleta. No entanto, um fator positivo foi o nível dos participantes na estrutura organizacional da empresa, todos estavam em nível estratégico ou no viés de gerenciamento de projetos de software ou no viés de alinhamento estratégico dos produtos e negócios de tecnologia da informação (TI). A Tabela 2 apresenta uma breve descrição da formação acadêmica dos participantes selecionados nas empresas “Empresa E1”, “Empresa E2” e “Empresa E3”.

Tabela 2. Descrição dos participantes da pesquisa

\begin{tabular}{ll}
\hline Empresa & Descrição \\
\hline Empresa E1 & $\begin{array}{l}\text { Especialista em gestão de TI. Exerce atividades de gerenciamento de desenvolvimento de } \\
\text { software e participa do corpo de governança de TI da empresa. }\end{array}$ \\
\hdashline Empresa E2 & $\begin{array}{l}\text { Graduado em administração com gestão em TI e exerce atividades comerciais na } \\
\text { empresa. }\end{array}$ \\
\hdashline Empresa E3 & Graduado em informática e exercer atividades de gestão da infraestrutura de TI. \\
\hline
\end{tabular}

Dentre os 04 (quatro) instrumentos de coleta de dados previstos na etapa de planejamento (documentação, registro em arquivos, observação e entrevista) apenas 02 (dois) foram empregados efetivamente. Esse fato decorreu das restrições impostas pelas 
empresas preocupadas em garantir a confidencialidade dos dados estratégicos e a privacidade dos colaboradores.

É importante ressaltar que a preparação da execução do plano foi analisada e customizada para cada empresa. Os principais motivos para a implementação do plano foram os obstáculos apresentados anteriormente e os fores contextuais de cada empresa. No entanto, os instrumentos precípuos foram passíveis de aplicação em todas as empresas e seguiram as etapas apresentadas na Figura 2.

A fase de coleta de dados incorporou entrevistas semiestruturadas e revisões de registros em arquivos. Para organizar os dados coletados e facilitar a aplicação da técnica de confiabilidade realizou-se uma análise preliminar.

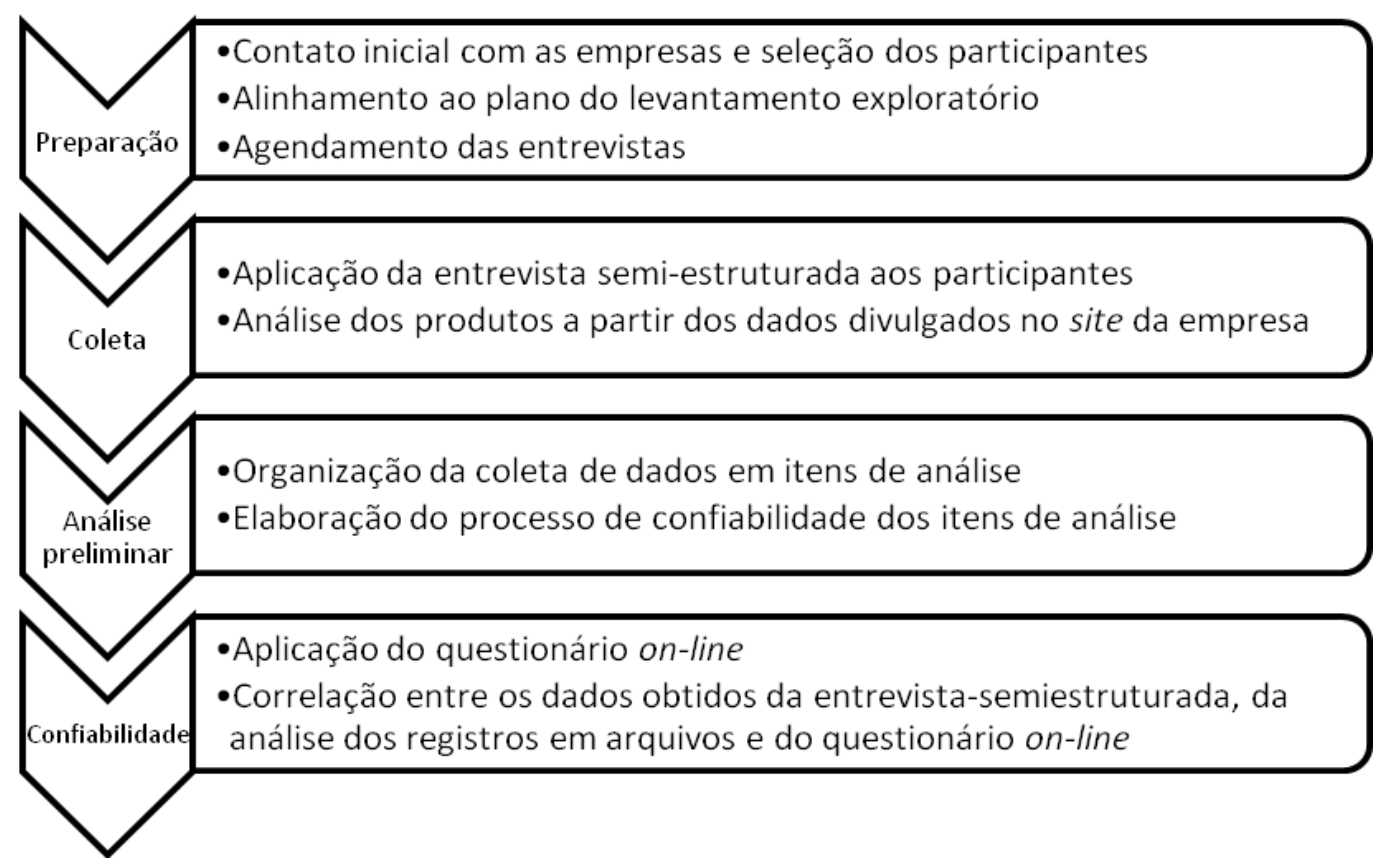

Figura 2. Atividades executadas em cada fase da etapa de execução da pesquisa.

\subsection{Coleta e análise preliminar dos dados}

A fase de preparação mitigou algumas ameaças ao estudo e permitiu a seleção dos participantes e a escolha dos instrumentos de coleta de dados com maior objetividade e confiança. Dois instrumentos foram aplicados, a entrevista semiestrutura, que implica na elaboração e aplicação de perguntas que envolvem as questões primárias e secundárias definidas na etapa de planejamento e a formulação de outras perguntas inerentes ao contexto e às circunstâncias da entrevista [Yin 2005][Martins 2006], e a revisão de registros em arquivos, que envolve a identificação e extração de dados contidos em meios físicos ou digitais.

Nas empresas “Empresa E1”, "Empresa E2” e “Empresa E3” os dados foram coletados por meio de duas fontes de evidências: entrevistas e registro em arquivos. A entrevista possibilitou a coleta de dados sobre a organização, os produtos, os indivíduos e os processos. O registro em arquivo ocorreu a partir de dados públicos apresentado pelas empresas em suas respectivas páginas da Internet e tornou possível a coleta de dados sobre os produtos de mercado da empresa. Na empresa "Empresa E1" também foi 
realizada uma breve observação de um dos softwares utilizado no gerenciamento dos projetos. Os respondentes das empresas foram respectivamente o gerente da área de desenvolvimento e testes, o diretor comercial e o diretor de novos negócios.

Os dados obtidos por meio dos instrumentos de coleta foram imbricados e organizados em 13 (treze) tópicos para facilitar a compreensão e a padronização do resultado dos itens de coleta. São eles:

- Estrutura organizacional em nível estratégico e de gerenciamento de projetos;

- Característica do produto de mercado;

- Seleção de recursos humanos;

- Alocação de recursos humanos;

- Modelo e metodologias de gerenciamento de projetos de software;

- Qualidade do produto e do processo de desenvolvimento;

- Programa de treinamento;

- Disseminação do conhecimento técnico;

- Riscos dos projetos de desenvolvimento de software móvel;

- Desafios dos projetos de desenvolvimento de software móvel;

- Indicadores (qualidade do produto, produtividade da equipe, desempenho da equipe, etc.);

- Ferramentas computacionais; e

- Alinhamento das ferramentas computacionais no gerenciamento dos projetos de software.

Cada tópico representa um grupo de características encontradas na pesquisa de campo que podem colacionar a forma de condução dos projetos com o propósito de confirmar ou negar as proposições de pesquisa.

\subsection{Confiabilidade dos dados coletados}

Nesta fase os dados obtidos pelos instrumentos de entrevista e registro em arquivo foram colacionados com um questionário para garantir a constância do resultado dos tópicos da análise preliminar.

A confiabilidade dos dados foi obtida por meio da técnica de equivalência. Segundo Martins (2005), a técnica é confiável se a correlação entre os resultados coletados são fortemente positivos. As nuances dessa técnica permitem aplicá-la em pesquisas cujos dados podem ser obtidos de duas ou mais fontes, como é o caso deste projeto de pesquisa.

Para mitigar o impacto de replicação de resposta por conveniência dos participantes aplicou-se o questionário em média 15 dias após a entrevista. Nesse ínterim, o questionário foi elaborado com base no resultado das entrevistas e procurou-se incorporar os relatos e aspectos prevalentes (Tabela 3). A técnica de equivalência por meio do questionário só não foi aplicada no tópico característica do produto de mercado, pois se alcançou a confiabilidade desse tópico a partir da equivalência entre as entrevistas em corroboração com a revisão dos dados disponíveis no site das empresas. 
Tabela 3. Apresentação resumida do questionário

\section{Questão}

Sobre o respondente

(1) Escolaridade e curso de formação. (2) Empresa e cargo. (3) Possui experiência em desenvolvimento de sistemas para dispositivos móveis? (4) Possui experiência em gerenciamento de projetos.

Sobre a empresa

(5) Quantidade de colaboradores no cargo ou função de desenvolvimento. (6) Quantidade de colaboradores no cargo ou função de gerenciamento. (7) A hierarquia organizacional da empresa é: (seleção do tipo de classificação conforme descrição) (8) Quais formas são utilizadas pela empresa para seleção de ovos colaboradores? (9) Existe algum processo formal de desenvolvimento de software utilizado pela empresa? (10) Existe algum formalismo referente ao gerenciamento de projetos utilizado pela empresa? Caso utilize um processo formal, este é baseado em qual(is) modelo(s) e metodologia(s)?

Sobre o gerenciamento de projetos

(11) Você considera o valor agregado e a forma de gerenciar os serviços e aplicações móveis diferente das outras modalidades de aplicação? (12) A empresa propõe a realização de uma avaliação formal por parte dos clientes/usuários com relação aos produtos ou ao processo de desenvolvimento? (13) Como o conhecimento é disseminado ou repassado para os colaboradores? (14) A seguir estão alguns dos desafios encontrados nos projetos de desenvolvimento de software para dispositivos móveis. Classifique em baixo impacto, médio impacto ou alto impacto. [lista de itens] Existem outros desafios de gerenciamento de projetos de mobilidade para serem considerados? Quais? (15) Quais indicadores listados são aplicados no gerenciamento de projetos? Existem outros indicadores para serem consideradas? Quais?

\section{Ferramentas computacionais}

(16) Marque as ferramentas de apoio utilizadas pela empresa no gerenciamento/acompanhamento dos projetos de desenvolvimento de software. (seleção das ferramentas apresentadas) (17) As ferramentas computacionais de gerenciamento utilizadas pela empresa suprem as necessidades dos gerentes ou coordenadores de projetos? Quais são as áreas deficientes?

\section{Análise e interpretação dos dados confiáveis}

Procurando sintetizar os dados coletados e confirmados na etapa de execução do projeto e correlacionar os resultados entre as empresas, construiu-se uma estrutura tabular para descrever detalhadamente cada tópico da análise preliminar. A Tabela 4 apresenta essa estrutura e descreve sucintamente os tópicos para cada empresa estudada.

Tabela 4. Descrição resumida dos tópicos de análise

\begin{tabular}{|c|c|c|c|}
\hline Tópicos & Empresa E1 & Empresa E2 & Empresa E3 \\
\hline $\begin{array}{l}\text { Estrutura } \\
\text { organizacional em } \\
\text { nível estratégico }\end{array}$ & $\begin{array}{l}\text { Hierarquizada com gestão } \\
\text { limitada por um corpo de } \\
\text { gestores. }\end{array}$ & $\begin{array}{l}\text { Hierarquizada apenas } \\
\text { entre o nível estratégico e } \\
\text { o nível operacional }\end{array}$ & $\begin{array}{l}\text { Fracamente hierarquizada } \\
\text { entre o nível estratégico e } \\
\text { o nível operacional. }\end{array}$ \\
\hline $\begin{array}{l}\text { Característica do } \\
\text { produto de } \\
\text { mercado }\end{array}$ & $\begin{array}{l}\text { Módulo mobile para os } \\
\text { profissionais de campo e } \\
\text { que integra com o sistema } \\
\text { de gestão do cliente. } \\
\text { Possui funcionalidades } \\
\text { específicas } \\
\text { customização limitada por } \\
\text { um core. }\end{array}$ & $\begin{array}{l}\text { Produto mobile voltado } \\
\text { aos profissionais de } \\
\text { campo e que integra com } \\
\text { sistemas de gestão. Possui } \\
\text { duas linhas, customizado } \\
\text { e não customizado } \\
\text { (software de prateleira). }\end{array}$ & $\begin{array}{l}\text { Plataforma de } \\
\text { desenvolvimento mobile } \\
\text { que segue a filosofia de } \\
\text { software como serviço. } \\
\text { Disponibiliza qualquer } \\
\text { serviço desenvolvido ou } \\
\text { customizado } \\
\text { plataforma on-line. }\end{array}$ \\
\hline $\begin{array}{l}\text { Qualidade do } \\
\text { produto ou do } \\
\text { processo de } \\
\text { desenvolvimento }\end{array}$ & $\begin{array}{l}\text { Não existe um processo } \\
\text { formal, } \\
\text { especulações. }\end{array}$ & $\begin{array}{l}\text { Não existe um processo } \\
\text { formal, } \\
\text { especulações. }\end{array}$ & $\begin{array}{lll}\text { Processo } & \text { formal } & \text { de } \\
\text { qualidade com base } & \text { na } \\
\text { ISO 9001. } & & \end{array}$ \\
\hline
\end{tabular}


Tabela 4. Descrição resumida dos tópicos de análise (continuação)

\begin{tabular}{|c|c|c|c|}
\hline Tópicos & Empresa E1 & Empresa E2 & Empresa E3 \\
\hline $\begin{array}{l}\text { Seleção de } \\
\text { recursos humanos }\end{array}$ & $\begin{array}{l}\text { O processo é composto } \\
\text { por duas entrevistas, uma } \\
\text { com o setor de recursos } \\
\text { humanos e a outra com o } \\
\text { gerente da área responsável } \\
\text { pela vaga ofertada, e a } \\
\text { realização de um teste de } \\
\text { conhecimento. }\end{array}$ & $\begin{array}{l}\text { O processo é composto } \\
\text { por meio de uma } \\
\text { entrevista com o diretor } \\
\text { de desenvolvimento. }\end{array}$ & $\begin{array}{l}\text { Processo de seleção } \\
\text { colaborativo composto } \\
\text { por uma entrevista com o } \\
\text { setor de recursos } \\
\text { humanos, uma dinâmica } \\
\text { com a equipe da empresa } \\
\text { e a realização de um teste } \\
\text { básico de conhecimento. }\end{array}$ \\
\hline $\begin{array}{l}\text { Alocação de } \\
\text { recursos humanos }\end{array}$ & $\begin{array}{l}\text { Alocação conforme os } \\
\text { projetos e as necessidades } \\
\text { específicas. }\end{array}$ & $\begin{array}{l}\text { Alocação conforme a } \\
\text { necessidade e demanda de } \\
\text { serviços. }\end{array}$ & $\begin{array}{l}\text { Alocação conforme os } \\
\text { projetos. }\end{array}$ \\
\hline $\begin{array}{l}\text { Modelos e } \\
\text { metodologias de } \\
\text { gerenciamento de } \\
\text { projetos de } \\
\text { software }\end{array}$ & $\begin{array}{l}\text { Metodologia } \\
\text { baseada nos modelos } \\
\text { Processual PMI e ITIL, } \\
\text { combinados com o } \\
\text { modelo de governança } \\
\text { CobiT. }\end{array}$ & $\begin{array}{l}\text { Em fase de adoção e } \\
\text { implantação do SCRUM } \\
\text { no processo operacional. }\end{array}$ & $\begin{array}{l}\text { Metodologia } \\
\text { composta pela Lean em } \\
\text { nível de gestão e, a } \\
\text { metodologia eXtreme } \\
\text { Programming (XP) e o } \\
\text { processo iterativo SCRUM } \\
\text { em nível operacional. }\end{array}$ \\
\hline $\begin{array}{l}\text { Programa de } \\
\text { treinamento }\end{array}$ & $\begin{array}{l}\text { Treinamento interno para } \\
\text { as áreas operacional e } \\
\text { gerencial. }\end{array}$ & $\begin{array}{l}\text { Não possui programas de } \\
\text { treinamento. }\end{array}$ & $\begin{array}{l}\text { Treinamentos ofertados } \\
\text { aos colaboradores, aos } \\
\text { clientes e a qualquer } \\
\text { interessado em conhecer o } \\
\text { produto. }\end{array}$ \\
\hline $\begin{array}{l}\text { Disseminação do } \\
\text { conhecimento }\end{array}$ & Documentos e manuais. & Documentos e manuais. & $\begin{array}{l}\text { Documentos, manuais e } \\
\text { reuniões de repasse de } \\
\text { conhecimento. }\end{array}$ \\
\hline $\begin{array}{l}\text { Riscos dos } \\
\text { projetos de } \\
\text { desenvolvimento } \\
\text { de software móvel }\end{array}$ & $\begin{array}{l}\text { Os principais riscos } \\
\text { selecionados pela empresa } \\
\text { são: seleção e alocação de } \\
\text { recursos humanos; } \\
\text { mudança de tecnologia de } \\
\text { desenvolvimento; } \\
\text { limitação dos dispositivos } \\
\text { e incompatibilidade de } \\
\text { dispositivos com } \\
\text { software. }\end{array}$ & $\begin{array}{lr}\text { Os principais riscos } \\
\text { selecionados pela empresa } \\
\text { são: mudança de } \\
\text { tecnologia } \\
\text { desenvolvimento; } \\
\text { limitação dos dispositivos } \\
\text { e dificuldade de gestão } \\
\text { dos recursos humanos. }\end{array}$ & $\begin{array}{l}\text { O principal risco } \\
\text { selecionado pela empresa } \\
\text { é a mudança de tecnologia } \\
\text { de desenvolvimento. }\end{array}$ \\
\hline $\begin{array}{l}\text { Desafios dos } \\
\text { projetos de } \\
\text { desenvolvimento } \\
\text { de software móvel }\end{array}$ & $\begin{array}{l}\text { Os principais desafios } \\
\text { selecionados pela empresa } \\
\text { são: incerteza na previsão } \\
\text { do cronograma e a } \\
\text { integração com sistemas } \\
\text { de gestão empresarial. }\end{array}$ & $\begin{array}{l}\text { Os principais desafios } \\
\text { selecionados pela empresa } \\
\text { são: incerteza na previsão } \\
\text { de custos e do cronograma; } \\
\text { integração e volatilidade do } \\
\text { mercado e dos dispositivos. }\end{array}$ & $\begin{array}{lr}\text { Os principais desafios } \\
\text { selecionados pela } & \text { empresa } \\
\text { são: integração } & \text { com } \\
\text { sistemas de gestão } & \\
\text { empresarial e a diversidade } & \\
\text { de aplicações e serviços. }\end{array}$ \\
\hline Indicadores & $\begin{array}{l}\text { Produtividade da equipe } \\
\text { de desenvolvimento, } \\
\text { ociosidade por recursos } \\
\text { humanos e artefatos, custo } \\
\text { dos colaboradores ou } \\
\text { artefatos e número de } \\
\text { ocorrência de novas } \\
\text { funcionalidades } \\
\text { manutenções. }\end{array}$ & $\begin{array}{l}\text { Número de ocorrências de } \\
\text { novas funcionalidades e } \\
\text { manutenções e rodízio } \\
\text { dos colaboradores nas } \\
\text { atividades. }\end{array}$ & $\begin{array}{l}\text { Qualidade do software, } \\
\text { produtividade da equipe } \\
\text { de desenvolvimento e } \\
\text { ocorrência de novas } \\
\text { funcionalidades, defeitos } \\
\text { e erros. }\end{array}$ \\
\hline
\end{tabular}


Tabela 4. Descrição resumida dos tópicos de análise (continuação)

\begin{tabular}{|c|c|c|c|}
\hline Tópicos & Empresa E1 & Empresa E2 & Empresa E3 \\
\hline $\begin{array}{l}\text { Ferramentas } \\
\text { computacionais }\end{array}$ & $\begin{array}{l}\text { Microsoft Project, Apache } \\
\text { Maven, planilhas de dados } \\
\text { e ferramentas desenvolvidas } \\
\text { internamente. }\end{array}$ & $\begin{array}{l}\text { Microsoft Project } \\
\text { planilhas de dados. }\end{array}$ & $\begin{array}{l}\text { Yammer, Kayako } \\
\text { planilhas de dados. }\end{array}$ \\
\hline $\begin{array}{l}\text { Alinhamento das } \\
\text { ferramentas } \\
\text { computacionais }\end{array}$ & $\begin{array}{l}\text { Suprem parcialmente as } \\
\text { necessitadas. }\end{array}$ & $\begin{array}{l}\text { Não suprem as } \\
\text { necessidades da empresa. }\end{array}$ & $\begin{array}{l}\text { Suprem as necessidades } \\
\text { da empresa. }\end{array}$ \\
\hline
\end{tabular}

A partir dos resultados da análise e interpretação alguns possíveis aspectos inusitados podem ser extraídos e observados a fim de identificar tendências e confrontar diferentes visões e perspectivas do gerenciamento de projetos de software. Por exemplo, as empresas "Empresa E1" e "Empresa E2" convergem para a mesma forma e característica de gerenciamento, por outro lado, a “Empresa E3" apresenta uma tendência divergente principalmente nos quesitos de mercado, de produto e da gestão de recursos humanos. Esse resultado também subsidia a caracterização do contexto móvel em relação a outros contextos de desenvolvimento de software.

\section{Resultados da pesquisa}

O processo sistemático do estudo resultou na especificação de 13 (treze) tópicos de pesquisa categorizados em 6 (seis) áreas. A categorização apresenta diferenças identificadas a partir do estudo na gestão de projetos de software entre o contexto de desenvolvimento clássico e o contexto de negócios móveis (Tabela 5). Entende-se como contexto clássico a construção moderna de software cujo processo de engenharia de software faz uso de modelos e padrões universais [Teixeira e Cukierman 2007] sistemas corporativos desenvolvidos sob uma perspectiva técnica.

Tabela 5. Diferenças identificadas entre a gestão de projetos de software clássico e móvel

\begin{tabular}{|c|c|c|}
\hline Área & Contexto Clássico & Contexto Móvel \\
\hline Escopo do produto & $\begin{array}{l}\text { - Desenvolvimento de produtos } \\
\text { genuínos (próprios e independentes } \\
\text { de outros sistemas) } \\
\text { - Normalmente transação on-line }\end{array}$ & $\begin{array}{l}\text { - Desenvolvimento de produtos de } \\
\text { integração com sistemas de } \\
\text { informação } \\
\text { - Transação on-line e off-line }\end{array}$ \\
\hline $\begin{array}{l}\text { Duração dos projetos } \\
\text { Recursos Humanos }\end{array}$ & $\begin{array}{l}\text { - Médio e longo prazo } \\
\text { - Processo de seleção específico } \\
\text { Equipes estáticas }\end{array}$ & $\begin{array}{l}\text { - Curto prazo } \\
\text { - Processo de seleção generalizado } \\
\text { Equipes dinâmicas }\end{array}$ \\
\hline Riscos & $\begin{array}{l}\text { - Baixo impacto de fatores externos } \\
\text { não regulatórios } \\
\text { - Médio impacto de fatores } \\
\text { tecnológicos } \\
\text { - Facilidade de encontrar mão de obra } \\
\text { qualificada }\end{array}$ & $\begin{array}{l}\text { - Médio impacto de fatores } \\
\text { externos não regulatórios } \\
\text { - Alto impacto de fatores } \\
\text { tecnológicos } \\
\text { - Dificuldade de encontrar mão de } \\
\text { obra qualificada }\end{array}$ \\
\hline $\begin{array}{l}\text { Planejamento } \\
\text { estratégico de mercado }\end{array}$ & $\begin{array}{l}\text { - Médio e longo prazo } \\
\text { - Previsão do mercado }\end{array}$ & $\begin{array}{l}\text { - Curto prazo } \\
\text { - Reação do mercado }\end{array}$ \\
\hline Custos & $\begin{array}{l}\text { - Teste em uma ou poucas } \\
\text { plataformas/equipamentos }\end{array}$ & $\begin{array}{l}\text { - Teste em várias } \\
\text { plataformas/equipamentos }\end{array}$ \\
\hline
\end{tabular}


A relação entre os contextos apresentados na Tabela 5 rejeita a hipótese nula e confirma que o gerenciamento de projetos de software depende da modalidade das aplicações. Também é possível analisar a veracidade das proposições do plano do levantamento exploratório (Tabela 6).

Um aspecto e resultado interessante do estudo foram às características e diferenças sobre as áreas categorizadas no contexto de desenvolvimento de software para dispositivos móveis. Apesar das áreas selecionadas apresentarem diferenças entre as empresas estudadas, observou-se que o propósito dos produtos e os riscos possuem pouca similaridade comparada a outros fatores.

Tabela 6. Confirmação das proposições do plano de estudo

\begin{tabular}{ll}
\hline Proposição & [SIM] [NÃO] \\
\hline Requer uma estrutura tecnológica e de mapeamento de riscos mais complexa & SIM \\
Fatores regulatórios são riscos do projeto relacionados aos fatores externos & NÃO \\
A infraestrutura de comunicação e a incompatibilidade tecnológica são & SIM \\
características/problemas encontrados no gerenciamento de projetos de & \\
software para negócios móveis & \\
Os recursos humanos devem possuir habilidades multidisciplinares & SIM \\
\hline
\end{tabular}

Salienta-se que a pesquisa foi realizada em três empresas, o que contribui para o levantamento das informações, mas não possibilita a generalização para todas as empresas.

\section{Trabalhos relacionados}

Machado e Freitas (2008) propõem em seu trabalho um modelo teórico para planejar a adoção de tecnologias móveis visando disponibilizar um material organizado para apoiar os gestores nos projetos de aquisição dessas tecnologias.

Unhelkar (2009) apresenta uma metodologia formal de transição para as organizações adotarem as tecnologias móveis em seu negócio. Sua metodologia oferece uma compreensão prática e uma abordagem estratégica de transição da gestão para negócios móveis - abrange toda a empresa para a forma móvel de trabalho.

Fouskas et al. (2005) sistematiza em um guia a perspectiva metodológica e interdisciplinar sobre a pesquisa de negócios móveis. Este trabalho estabelece diretrizes para identificar os desafios na adoção e uso das tecnologias móveis ao negócio.

Os três trabalhos formam as bases da pesquisa e da caracterização do contexto de desenvolvimento de software para negócios móveis. No entanto, esta pesquisa diferencia dos demais trabalhos por ser estrita ao contexto gerencial de projetos de desenvolvimento de software.

\section{Considerações finais}

A independência espacial e temporal são características da tecnologia móvel que impulsionaram as organizações a desenvolverem softwares para atender novas perspectivas de negócio. Segundo o Relatório Anual 2010 [Anatel 2010] no último ano o número de acessos a conteúdos móveis e a utilização de serviços fornecidos pelas tecnologias móveis interativas e corporativas mais que triplicou, configurando um cenário crescente e dinâmico. As novas oportunidades de negócios caracterizadas pelo uso das tecnologias móveis passam por um período transitório com novos desafios e 
riscos, entretanto pesquisas e estudos são realizados com o objetivo de mitigar os impactos da adoção e do desenvolvimento de software para o contexto m-business.

Este trabalho buscou identificar desafios e riscos encontrados em projetos de desenvolvimento de software para m-business e caracterizar os aspectos do gerenciamento de projetos que divergem entre os contextos de desenvolvimento móvel e clássico. É observado pela análise e interpretação dos dados, bem como os resultados, que o objetivo da pesquisa foi alcançado, contudo os resultados estão delimitados por três realidades distintas e não podem ser generalizados.

Como trabalhos futuros sugerem-se uma pesquisa minuciosa e detalhada em pontos específicos do gerenciamento de projetos de software para dispositivos móveis, tais como, riscos, custos e recursos humanos, a aplicação do protocolo de pesquisa proposto para outras empresas e a integração dos softwares móveis com sistemas de gestão. Também se espera que o trabalho contribua para a fundamentação de novas pesquisas e estudos.

\section{Agradecimentos}

Agradecimento a Coordenação de Aperfeiçoamento de Pessoal de Nível Superior (CAPES) pelo financiamento por meio do Programa Nacional de Cooperação Acadêmica (PROCAD) - PROCAD-NF 191/2007 (ICMC-USP/UEM/PUC-RS) - que viabilizou a execução da pesquisa.

\section{Referências}

Anatel - Agência Nacional de Telecomunicações. (2010). Relatório Anual 2010.

Fouskas, K. G., Giaglis, G. M., Kourouthanassis, P. E., Karnoukos, S., Pitsillides, and A., Stylianou, M. (2005) “A roadmap for research in mobile business”, In: International Journal of Mobile Communications (IJMC), v.3, n.4.

Machado, C. B. e Freitas, H. (2008). "Planejamento de Iniciativas de Adoção de Tecnologias Móveis”. Revista GEPROS, ano 4, n. 1, p. 101-115.

Mafra, S. N. e Travassos, G. H. (2006) "Estudos Primários e Secundários apoiando a busca por Evidência na Engenharia de Software”. Rio de Janeiro: Programa de Engenharia de Sistemas e Computação. RT-ES 687/06.

Martins, G. A. (2006) "Sobre confiabilidade e validade”. Revista Brasileira de Gestão de Negócios. São Paulo, v. 8, p. 1-12.

Mohelska, H. (2010) "Mobile Technologies and Their Use in a Company”, In: World Multiconference on Applied Economics, Business and Development (AEBD), 2nd, 2010, Kantaoui, Sousse, Tunisia. Applied Economics, Business and Development. WSEAS Press, may. p. 141-146.

Teixeira, C. A. N. e Cukierman, H. L. (2007) "Por que Falham Projetos de Implantação de Processos de Software?”, In: Simpósio Brasileiro de Qualidade de Software/WOSES (Worksho Um Olhar Sociotécnico sobre a Engenharia de Software). Porto de Galinhas - PE. $3^{\circ}$. WOSES. Rio de Janeiro: PESC/COPPE - UFRJ. p. 1-12.

Unhelkar, B. (2009), Mobile Enterprise Transition and Management. Advanced and emerging communications technologies series. Auerbach Publications Boston, MA, USA.

Vos, I. and Klein, P. (2002), The Essential Guide to Mobile Business, Prentice Hall.

Yin, R. K. (2005), Estudo de Caso: Planejamento e Métodos. 3. ed., Porto Alegre, Bookman. 